\title{
Changing glucose control target and risk of surgical site infection in a Southeast Asian population
}

\author{
Roderica Rui Ge Ng, ${ }^{\text {a }}$ Aung Myat Oo, MBBS, MCTM, ${ }^{\text {b }}$ Weiling Liu, BSc (Hons), \\ Teing Ee Tan, MBBS, FRCS Ed (Gen Surg), ${ }^{\mathrm{c}}$ Lian Kah Ti, MBBS, MMed, ${ }^{\mathrm{a}, \mathrm{d}}$ and \\ Sophia Tsong Huey Chew, MBBS, MMed, FANZCA ${ }^{\text {e,f }}$
}

\begin{abstract}
Objective: Hyperglycemia is associated with surgical site infection and mortality in cardiac surgical patients. There is overriding evidence that glycemic control improves morbidity and mortality. However, the optimal glucose range in these patients remains controversial. Intensive glucose control can lead to mortality among critically ill adults because of episodic, moderate hypoglycemia. Therefore, we examined the effect of different glucose target control on the incidence of surgical site infection in our prospective cohort of diabetic and nondiabetic patients undergoing coronary artery bypass grafting.
\end{abstract}

Methods: Data from 1442 patients who underwent elective coronary artery bypass grafting at a tertiary heart center in Singapore from 2009 to 2011 were obtained. The first glucose level on arrival in the cardiothoracic intensive care unit was set at 4 to $8 \mathrm{mmol} / \mathrm{L}$ in 2009 and 2010 and 4 to $10 \mathrm{mmol} / \mathrm{L}$ in 2011 . Glucose control was achieved with intravenous insulin infusion with a strict glucose monitoring protocol. Clinical covariates were analyzed, with surgical site infection as the primary outcome.

Results: The majority of patients presenting for coronary artery bypass grafting were male, Chinese, and diabetic. Diabetic patients had significantly higher glucose levels on arrival in the cardiothoracic intensive care unit. The change in target glucose control was independently associated with an increase in surgical site infection (odds ratio, 2.280; 95\% confidence interval, 1.250-4.162; $P=.007$ ). Subgroup analysis revealed that unlike in nondiabetic patients, a less stringent target was independently associated with a significant increase in surgical site infection incidence from $2.2 \%$ to $6.9 \%$ for the diabetic patients (odds ratio, $3.131 ; 95 \%$ confidence interval, $1.431-6.851 ; P=.004)$.

Conclusions: A target blood glucose of less than $8 \mathrm{mmol} / \mathrm{L}$ was associated with a lower incidence of surgical site infection in diabetic patients presenting for elective coronary artery bypass grafting in the local Southeast Asian population. (J Thorac Cardiovasc Surg 2015;149:323-8)

See related commentary on pages 328-9.

Hyperglycemia is associated with adverse outcomes in cardiac surgical patients, including increased morbidity, such as surgical site infection (SSI), and mortality. ${ }^{1,2}$ Patients with insulin resistance or diabetes mellitus (DM) who undergo coronary artery bypass grafting (CABG) may develop hyperglycemia. ${ }^{3}$ Factors

\footnotetext{
From the Yong Loo Lin School of Medicine, ${ }^{a}$ National University of Singapore, Singapore; Department of Quality Management, ${ }^{\mathrm{b}}$ Singapore General Hospital, Singapore; Department of Anesthesia, ${ }^{c}$ National University Health System, Singapore; Department of Cardiothoracic Surgery, ${ }^{\mathrm{d}}$ National Heart Centre, Singapore; Department of Anesthesiology, ${ }^{\mathrm{e}}$ Singapore General Hospital, Singapore; and Department of Cardiovascular and Metabolic Disorders, ${ }^{f}$ Duke-NUS Graduate Medical School, Singapore.

Disclosures: Authors have nothing to disclose with regard to commercial support. Received for publication March 28, 2014; revisions received Aug 2, 2014; accepted for publication Aug 20, 2014; available ahead of print Oct 16, 2014.

Address for reprints: Sophia Tsong Huey Chew, MBBS, MMed, FANZCA, Department of Anaesthesiology, Singapore General Hospital, 20 College Rd, Academia, Level 5, Singapore 169856 (E-mail: rnsctlk@gmail.com). $0022-5223 / \$ 36.00$

Copyright (C) 2015 by The American Association for Thoracic Surgery http://dx.doi.org/10.1016/j.jtcvs.2014.08.076
}

contributing to the increase in insulin resistance include increased levels of catecholamines, growth hormone, and cortisol as a stress response to surgery or from pharmacologic agents given perioperatively, such as inotropes and beta-blockers.

There is overriding evidence that glycemic control improves both morbidity, such as SSI, and mortality in patients undergoing CABG. $^{4-6}$ However, the optimal range for blood glucose in cardiac surgical patients remains an area of controversy, and it is unclear whether the target control is different between diabetic and nondiabetic patients. The general consensus remains that glucose levels greater than $200 \mathrm{mg} / \mathrm{dL}(>11.1 \mathrm{mmol} / \mathrm{L})$ is detrimental, but the lower limit and the tightness of control is debatable. In the original study of tight glucose control by Van den Berghe and colleagues, ${ }^{7,8}$ a glucose control between 81 and $108 \mathrm{mg} / \mathrm{dL}$ (4 and $6 \mathrm{mmol} / \mathrm{L}$ ) was advocated, but in a recent multicenter trial (Normoglycemia in Intensive Care Evaluation-Survival Using Glucose Algorithm Regulation [NICE-SUGAR]), ${ }^{9}$ intensive glucose control actually led to increased mortality among critically ill adults, primarily because of episodes of moderate hypoglycemia. Therefore, we 


\section{Abbreviations and Acronyms \\ $\mathrm{CABG}=$ coronary artery bypass grafting \\ CI \\ CT-ICU = cardiothoracic intensive care unit \\ $\mathrm{DM} \quad=$ diabetes mellitus \\ SSI $\quad=$ surgical site infection \\ NICE-SUGAR $=$ Normoglycemia in Intensive Care \\ Evaluation-Survival Using \\ Glucose Algorithm Regulation}

embarked on this study to determine the incidence of SSI at both the sternotomy and the graft harvest sites in our population and to study the effect of the change in glucose target control from 75 to $150 \mathrm{mg} / \mathrm{dL}$ ( $4-8 \mathrm{mmol} / \mathrm{L}$ ) to 75 to $180 \mathrm{mg} / \mathrm{dL}(4-10 \mathrm{mmol} / \mathrm{L})$ on the incidence of SSI.

Given that the prevalence of DM in our local population who present for CABG is approximately $50 \%$, which is higher than that of the Western population, ${ }^{10-12}$ it is important for us to determine an optimal blood glucose range to reduce the incidence of SSI and subsequent mortality. Therefore, we also aimed to study the difference in target control between diabetic and nondiabetic patients in our local Asian population undergoing CABG.

\section{PATIENTS AND METHODS \\ Patient Selection}

After institutional review board approval, we prospectively followed up 1481 patients who underwent elective isolated CABG with open vein harvesting between January 1, 2009, and December 31, 2011, at a tertiary heart center in Singapore. Written informed consent was obtained from all patients. All patients, regardless of their DM status, were included in this study. However, 39 patients were excluded because there were incomplete data for analysis. Therefore, the total number of patients who met the inclusion and exclusion criteria was 1442 .

\section{Targets for Glucose Control in Insulin Protocol}

Between 2009 and 2010, as part of a clinical improvement project, the target first glucose on arrival in the cardiothoracic intensive care unit (CT-ICU) was set at 4 to $8 \mathrm{mmol} / \mathrm{L}$. The upper limit was increased to $10 \mathrm{mmol} / \mathrm{L}$ in 2011 on the basis of the suggested guidelines of the Society of Thoracic Surgeons Practice Guideline series: Blood Glucose Management During Adult Cardiac Surgery. ${ }^{13}$ Blood glucose targets were maintained via intravenous insulin with a sliding scale. Hyperglycemia and hypoglycemia were defined as greater than $11.1 \mathrm{mmol} / \mathrm{L}$ and less than $4.0 \mathrm{mmol} / \mathrm{L}$, respectively.

\section{Postoperative Glucose Monitoring}

All patients undergoing elective CABG during the study period had their blood glucose level monitored immediately on arrival to the CTICU. This level is a surrogate marker of the intraoperative glucose control. In the postoperative period in the CT-ICU, blood glucose was monitored every 2 to 4 hours, and more frequently if needed, up to the first 48 hours. All blood glucose levels were measured with standard point-of-care analyzers in the hospital. All glucose readings of a patient were measured from the same point-of-care machine.

\section{Postoperative Surgical Site Infection}

The primary outcome of this study was SSI. This includes both superficial (graft site) and deep (sternal) infection. An infection control nurse who was blinded to the study assessed the patients daily until the day of discharge for evidence of infection.

\section{Surgical and Perfusion Management}

All CABG procedures at our institution were performed with blood cardioplegia as the method of myocardial protection. The conditions and conduct of cardiopulmonary bypass remained constant throughout the study period.

\section{Statistical Analysis}

Population demographics, medical history, preoperative risk assessment, intraoperative variables, and postoperative outcomes were analyzed descriptively. Univariate analysis was performed using a Mann-Whitney $U$ test for continuous variables and Fisher exact test for categorical variables. The factors from the univariate analysis with $P<.05$ were included in the multivariate logistic regression model for further analysis.

One-way analysis of variance with post hoc Bonferroni correction was done to calculate the statistical significance when comparing the diabetic and nondiabetic patients with and without SSI. All statistical analyses were performed using IBM SPSS version 21.0. (IBM, Armonk, NY).

\section{RESULTS}

Between 2009 and 2011, a total of 1481 patients underwent elective isolated CABG with open vein harvesting. Complete data were captured for 1442 of these patients, and they were subsequently analyzed.

\section{Patient Demographics}

There was no significant change in patient profile over the 3 years (Table 1$)$.

\section{Differences Between Diabetic and Nondiabetic Patients}

There was a significantly larger proportion of female patients who were diabetic compared with the male patients. More Indians were diabetic, and this was consistent over the study period. Median preoperative serum glucose level was significantly higher in the diabetic population $(8.2$ $\mathrm{mmol} / \mathrm{L})$ than in the nondiabetic population $(5.9 \mathrm{mmol} / \mathrm{L})$. Likewise, glycosylated hemoglobin A1c among diabetic patients was significantly higher at $7.5 \%$ (25th-75th percentile: $6.7 \%-8.6 \%)$ than in nondiabetic patients, $5.8 \%$ (25th-75th percentile: $5.6 \%-6.1 \%$ ) (Table 2).

The durations of both cardiac bypass and surgery were similar in the cohorts over the 3 years. Diabetic patients had significantly higher levels of the first glucose on arrival to the CT-ICU and up to 48 hours postoperatively in comparison with their nondiabetic counterparts $(P<.001)$. The incidence of hyperglycemia within the first 48 hours on arrival to the ICU was significantly higher for the diabetic patients $(P<.001)$ (Table 2$)$. 
TABLE 1. Demographic profile of patients who underwent coronary artery bypass grafting

\begin{tabular}{|c|c|c|c|c|}
\hline Demographics & $\begin{array}{l}\text { Glucose target } 4-8 \mathrm{mmol} / \mathrm{L} \\
(\mathrm{n}=1019)\end{array}$ & $\begin{array}{l}\text { Glucose target } 4-10 \mathrm{mmol} / \mathrm{L} \\
\qquad(\mathrm{n}=423)\end{array}$ & Overall $(n=1442)$ & $P$ value \\
\hline Age (y) & $60.0(64.0-67.0)$ & $61.0(54.0-67.0)$ & $60.0(54.0-67.0)$ & 485 \\
\hline Gender & & & & .900 \\
\hline Male & $867(85.1)$ & $361(85.3)$ & $1228(85.2)$ & \\
\hline Female & $152(14.9)$ & $62(14.7)$ & $214(14.8)$ & \\
\hline Race & & & & .374 \\
\hline Chinese & $690(67.7)$ & $274(64.8)$ & 964 (66.9) & \\
\hline Malay & $139(13.6)$ & $71(16.8)$ & $210(14.6)$ & \\
\hline Indian & $129(12.7)$ & $57(13.5)$ & $186(12.9)$ & \\
\hline Others & $61(6.0)$ & $21(5.0)$ & $82(5.7)$ & \\
\hline $\mathrm{DM}$ & $550(54.0)$ & $216(51.1)$ & $766(53.1)$ & .313 \\
\hline Hypertension & $762(74.8)$ & $324(76.6)$ & $1086(75.3)$ & .424 \\
\hline Ejection fraction $(<30 \%)$ & $70(6.9)$ & $29(7.0)$ & $99(6.9)$ & .904 \\
\hline euroSCORE logistic & $2.3(1.5-4.3)$ & $2.0(1.3-3.2)$ & $2.2(1.4-4.0)$ & $<.001$ \\
\hline
\end{tabular}

Data presented as $\mathrm{n}(\%)$ or median (25th-75th percentile). DM, Diabetes mellitus; euroSCORE, European System for Cardiac Operative Risk Evaluation.

\section{Incidence of Surgical Site Infection}

The overall incidence of SSI was $2.4 \%$ when the glucose target was between 4 and $8 \mathrm{mmol} / \mathrm{L}$, whereas the incidence increased to $5.2 \%$ when the upper limit of glucose control was increased to $10 \mathrm{mmol} / \mathrm{L}$ (Table 3 ). From the multivariate model, the change to a less stringent glucose control was independently associated with a risk of higher incidence of SSI (odds ratio, 2.280; 95\% confidence interval [CI], 1.250-4.162; $P=.007$ ) (Table 4).

After stratifying the patients according to their diabetic status, the odds of a higher incidence of SSI among diabetic patients who had a less stringent glucose control was significantly higher than among diabetic patients with a more stringent glucose control (odds ratio, 3.131; 95\% CI, $1.431-6.851 ; P=.004)$. However, this was not significant for the nondiabetic patients $(95 \%$ CI, 0.543-3.738; $P=.472)$ when the glucose target changed.

\section{Hypoglycemia on Arrival at Cardiothoracic Intensive Care Unit}

The overall incidence of hypoglycemia was $2.1 \%$. The incidence of hypoglycemia increased from $1.8 \%$ to $2.8 \%$ when the glucose target changed from 4 to $8 \mathrm{mmol} / \mathrm{L}$ to 4 to $10 \mathrm{mmol} / \mathrm{L}$, although the increase was not significant $(P=.359)$. The incidence of hypoglycemia was not significantly different between the diabetic patients $(2.7 \%)$ and nondiabetic patients $(1.4 \%)(P=.146)$.

\section{Average Length of Stay and In-Hospital Mortality}

The median length of stay of patients with SSI was higher in the diabetic group (8.0 days; 25 th-75th percentile: 6.0 11.0 days) compared with the nondiabetic group (7.0 days; 25 th-75th percentile: $6.0-10.0$ days), although this difference was not shown to be statistically significant $(P=.543)$.

TABLE 2. Comparison of diabetic and nondiabetic patients with univariate analysis

\begin{tabular}{|c|c|c|c|c|}
\hline Variables & Diabetic $(n=766)$ & Nondiabetic $(n=676)$ & Overall $(n=1442)$ & $P$ value \\
\hline \multicolumn{5}{|l|}{ Demographics } \\
\hline Gender: female & $147(19.2)$ & $67(9.9)$ & $214(14.9)$ & $<.001$ \\
\hline Race & & & & $<.001$ \\
\hline Chinese & 465 (60.7) & $499(73.8)$ & $964(66.8)$ & \\
\hline Malay & $121(15.8)$ & $89(13.2)$ & $210(14.6)$ & \\
\hline Indian & $31(17.1)$ & $55(8.1)$ & $186(12.9)$ & \\
\hline Others & $49(6.4)$ & $33(4.9)$ & $82(5.7)$ & \\
\hline Preoperative serum glucose $(\mathrm{mmol} / \mathrm{L})$ & $8.2(6.3-10.9)$ & $5.9(5.2-6.9)$ & $6.8(5.6-8.9)$ & $<.001$ \\
\hline Preoperative HbA1c (\%) & $7.5(6.7-8.6)$ & $5.8(5.6-6.1)$ & $7.2(6.3-8.3)$ & $<.001$ \\
\hline \multicolumn{5}{|l|}{ Intraoperative parameters } \\
\hline Bypass time (min) & $90.0(74.0-107.0)$ & $91.0(76.0-111.0)$ & $90.0(75.0-109.0)$ & .087 \\
\hline Aortic crossclamp time (min) & $49.0(39.0-59.0)$ & $49.0(40.0-61.0)$ & $49.0(39.0-60.0)$ & .164 \\
\hline No. of vein graft(s) & $3.0(3.0-4.0)$ & $3.0(2.0-4.0)$ & $3.0(3.0-4.0)$ & .149 \\
\hline \multicolumn{5}{|l|}{ Postoperative parameters } \\
\hline First serum glucose on arrival to CT-ICU (mmol/L) & $7.4(6.5-8.9)$ & $6.9(6.2-8.1)$ & $7.2(6.3-8.6)$ & $<.001$ \\
\hline Highest serum glucose level within first $48 \mathrm{~h}$ in CT-ICU $(\mathrm{mmol} / \mathrm{L})$ & $13.2(11.2-15.3)$ & $9.9(8.8-11.3)$ & $11.4(9.5-13.8)$ & $<.001$ \\
\hline Hyperglycemia within first $48 \mathrm{~h}$ in CT-ICU & $570(75.6)$ & $184(27.6)$ & $754(53.1)$ & $<.001$ \\
\hline
\end{tabular}

Data presented as n (\%) for or median (25th-75th percentile). CT-ICU, Cardiothoracic intensive care unit; HbAlc, glycosylated hemoglobin. 
TABLE 3. Incidence of surgical site infection and serum glucose on arrival to cardiothoracic intensive care unit

\begin{tabular}{|c|c|c|c|}
\hline & Glucose target $4-8 \mathrm{mmol} / \mathrm{L}$ & Glucose target $4-10 \mathrm{mml} / \mathrm{L}$ & $P$ value \\
\hline Overall & $(\mathrm{n}=1019)$ & $(\mathrm{n}=423)$ & \\
\hline SSI & $24(2.4)$ & $22(5.2)$ & .008 \\
\hline First serum glucose on arrival to CT-ICU (mmol/L) & $7.2(6.2-8.5)$ & $7.3(6.5-8.8)$ & .011 \\
\hline Diabetic & $(\mathrm{n}=550)$ & $(\mathrm{n}=216)$ & \\
\hline SSI & $12(2.2)$ & $15(6.9)$ & .003 \\
\hline First serum glucose on arrival to CT-ICU $(\mathrm{mmol} / \mathrm{L})$ & $7.4(6.4-8.8)$ & $7.6(6.7-9.3)$ & .009 \\
\hline Nondiabetic & $(\mathrm{n}=469)$ & $(\mathrm{n}=207)$ & \\
\hline SSI & $12(2.6)$ & $7(3.4)$ & .615 \\
\hline First serum glucose on arrival to CT-ICU (mmol/L) & $6.8(6.2-8.1)$ & $7.0(6.2-8.2)$ & .276 \\
\hline
\end{tabular}

Data presented as n (\%) or median (25th-75th percentile). CT-ICU, Cardiothoracic intensive care unit; SSI, surgical site infection.

There was no mortality among patients with SSI in both the diabetic and nondiabetic patient groups. Mortality rates did not differ significantly for those without SSI between the diabetic $(1.8 \%)$ and nondiabetic $(1.1 \%)$ patient populations $(P=.368)$. There was no mortality among patients with SSI in both the diabetic and nondiabetic patient groups.

\section{DISCUSSION}

Our study shows that the change in the upper limit of glucose control from $8 \mathrm{mmol} / \mathrm{L}$ in 2010 to $10 \mathrm{mmol} / \mathrm{L}$ in 2011 resulted in a significantly higher rate of SSI in the cohort of diabetic patients presenting for elective CABG. This concurs with previous studies that hyperglycemia is associated with infection. 6,7 However, our study is the first to look at changing target levels of glucose that are still within the recommended guidelines. Tight glycemic control to a level less than $8 \mathrm{mmol} / \mathrm{L}$ is independently associated with a lower rate of infection in the diabetic patients in our local population.

\section{Hyperglycemia and Surgical Site Infection}

Patients undergoing CABG are at risk of hyperglycemia for a variety of factors. These include patients with coexisting DM or hyperglycemia could develop secondary to surgical stress, inflammation, sympathomimetic drugs, or increased insulin resistance.

Hyperglycemia is a known risk factor for infection because it impedes the normal physiologic responses to

TABLE 4. Multivariate analysis of perioperative risk factors associated with surgical site infection

\begin{tabular}{lccc}
\hline \multicolumn{1}{c}{ Variables } & OR & $\mathbf{9 5} \%$ CI & $\boldsymbol{P}$ value \\
\hline Glucose target: $4-10 \mathrm{mmol} / \mathrm{L}$ & 2.280 & $1.250-4.162$ & .007 \\
Gender: male & 0.477 & $0.235-0.966$ & .040 \\
Age (y) & - & $0.958-1.024$ & .578 \\
DM & - & $0.642-2.239$ & .569 \\
First serum glucose on arrival & - & $0.922-1.232$ & .387 \\
$\quad$ to CT-ICU (mmol/L) & & & \\
\hline
\end{tabular}

CI, Confidence interval; $C T$-ICU, cardiothoracic intensive care unit; $O R$, odds ratio; $D M$, diabetes mellitus. infection. ${ }^{14-16}$ In vivo studies show that hyperglycemia is associated with accelerated nonenzymatic glycosylation of proteins or the nonenzymatic addition of sugar molecules to the exposed lysine residues on extracellular proteins. Short-term glycosylation of immunoglobulins inactivates them, and glycosylation of newly synthesized collagen is associated with increased collagenase activity and decreased wound collagen content, thus impairing wound healing. ${ }^{17}$ Furthermore, hyperglycemia impairs leukocyte function, including abnormalities in granulocyte adherence, impaired phagocytosis, delayed chemotaxis, and depressed bactericidal activity. ${ }^{18}$ The degree of hyperglycemia that has been shown to impair phagocytic function, both in vivo and in vitro, is approximately 200 $\mathrm{mg} / \mathrm{dL}(11.1 \mathrm{mmol} / \mathrm{L}){ }^{19}$ More important, the degree of phagocytic impairment can be reversed with control of glucose level.

\section{Difference in Glucose Control Between Nondiabetic and Diabetic Patients}

Our study shows that changing the upper limit of glucose control has no effect on infection rate for the nondiabetic patient. The median blood glucose on arrival to the CTICU did not vary significantly when the upper limit of glucose target was increased to $10 \mathrm{mmol} / \mathrm{L}$.

However, there was a significant increase in the percentage of diabetic patients with SSI when the upper limit of glucose target was increased. This is despite the median glucose levels on arrival in CT-ICU, which ranged from 7.4 to $7.6 \mathrm{mmol} / \mathrm{L}$, being within the prescribed target. Our study clearly shows that the target level to reduce SSI in cardiac surgery is at less than $10 \mathrm{mmol} / \mathrm{L}$ and might be better at less than $8 \mathrm{mmol} / \mathrm{L}$ in the local diabetic population.

Our study contrasts with the guidelines recommended by the Society of Thoracic Surgeons. ${ }^{13}$ The more lenient guidelines of the Society of Thoracic Surgeons was in part attributed to evidence that intensive blood glucose control less than $6 \mathrm{mmol} / \mathrm{L}$ led to higher mortality. ${ }^{9}$ We postulate the following reasons why this guideline might not apply to the local diabetic population. 


\section{Preoperative Glucose Control in Diabetic Patients}

Our study population is different from the Western population in that approximately $50 \%$ of our patients who present for cardiac surgery have DM. ${ }^{10,11}$ This is higher than the $30 \%$ to $40 \%$ reported by our Western counterparts. ${ }^{12}$

Preoperative diabetic control may also differ between our Asian population and the Western population. This is reflected in the preoperative hemoglobin A1c level, which averages $7.5 \%$ in the local diabetic population presenting for cardiac surgery, showing that the preoperative diabetic control is suboptimal. This means there is a prolonged exposure to the hyperglycemic milieu with more pronounced changes in their immune function. This may be a reason why an aggressive approach to the perioperative control of blood glucose is needed in our population, particularly in those with DM.

\section{Demographics of Diabetic Patients}

There is a racial difference in the patients with DM presenting for CABG. Indian and Malays have a higher proportion of diabetic patients. It has been reported that in Singapore, Indians and Malays are more obese than Chinese. ${ }^{20,21}$ Because DM and obesity are components of the metabolic syndrome, further modulation of the immune response by this race effect needs to be considered. A genetic modification to the immune response cannot be ruled out in these patients, who also require tighter diabetic control as such. Socioeconomic status, including education and diet control, are contributory factors that have not been specifically looked into in this study, which may shed light on the high incidence of DM in these races and their predisposition to infection postoperatively.

\section{Tight Glucose Control and Hypoglycemia}

One of the dangers of a tight control of glucose is that of hypoglycemia. In the NICE-SUGAR trial, severe hypoglycemia (blood glucose level $<2.2 \mathrm{mmol} / \mathrm{L}$ ) was reported in $6.8 \%$ of patients receiving intensive control of their blood glucose. ${ }^{9}$ Our study shows that there is no significant change in the incidence of hypoglycemia between diabetic and nondiabetic patients on arrival to the CT-ICU and that there was no major adverse outcome. This can be attributed to the vigilant and regular monitoring of these patients both intraoperatively and up to the first 48 hours postoperatively. The end point of 48 hours postoperatively was chosen because most patients who present electively for CABG would have been extubated and started on oral feeds by then. The use of continuous insulin infusion also ensures more consistent delivery of the drug easing peaks and troughs in the plasma level. ${ }^{22}$ Therefore, the key to optimizing glucose control is in constant monitoring and adjustment of the level, which is time-consuming and tedious. A future development that will enhance care will be that of an automated closed-loop system of glucose monitoring and adjustment in the insulin delivery. ${ }^{23}$

\section{Study Strengths and Limitations}

The strength of this project is that we studied the effect of changing glucose control in a similar cohort in a constant environment over time. The blood glucose level was controlled both intraoperatively and up to the first 48 hours postoperatively in a protocol-driven manner.

The major limitation of this study is that this was a nonrandomized study comparing sequential groups of patients. However, the cohorts over the 3 years remained fairly homogenous and serve to mitigate against this limitation. We also did not study other factors, such as blood transfusion, that may contribute to increase infection.

\section{CONCLUSIONS}

A target blood glucose level of less than $8 \mathrm{mmol} / \mathrm{L}$ was independently associated with a lower incidence of SSI in diabetic patients presenting for elective CABG in the local Southeast Asian population. The major side effect of hypoglycemia was overcome through constant and vigilant blood glucose monitoring.

\section{References}

1. Carson JL, Scholz PM, Chen AY, Peterson ED, Gold J, Schneider SH. Diabetes mellitus increases short-term mortality and morbidity in patients undergoing coronary artery bypass graft surgery. J Am Coll Cardiol. 2002;40: 418-23.

2. Szabó Z, Håkanson E, Svedjeholm R. Early post-operative outcome and medium-term survival in 540 diabetic and 2239 nondiabetic patients undergoing coronary artery bypass grafting. Ann Thorac Surg. 2002;74:712-9.

3. Mills NL, Beaudet RL, Isom OW, Spencer FC. Hyperglycemia during cardiopulmonary bypass. Ann Surg. 1973;177:203-5.

4. Furnary AP, Gao G, Grunkemeier GL, Wu Y, Zerr KJ, Bookin SO, et al. Continuous insulin infusion reduces mortality in patients with diabetes undergoing coronary artery bypass grafting. J Thorac Cardiovasc Surg. 2003;125:1007-21.

5. Zerr KJ, Furnary AP, Grunkemeier GL, Bookin S, Kanhere V, Starr A. Glucose control lowers the risk of wound infection in diabetics after open heart operations Ann Thorac Surg. 1997;63:356-61.

6. Furnary AP, Zerr KJ, Grunkemeier GL, Starr A. Continuous intravenous insulin infusion reduces the incidence of deep sternal wound infection in diabetic patients after cardiac surgical procedures. Ann Thorac Surg. 1999;67: 352-60.

7. Van den Berghe G, Wouters P, Weekers F, Verwaest C, Bruyninckx F, Schetz M, et al. Intensive insulin therapy in the critically ill patients. $N$ Engl J Med. 2001; 345:1359-67.

8. Van den Berghe G, Wilmer A, Hermans G, Meersseman W, Wouters PJ, Milants I, et al. Intensive insulin therapy in the medical ICU. $N$ Engl J Med. 2006;354:449-61.

9. NICE-SUGAR Study Investigators, Finfer S, Chittock DR, Su SY, Blair D, Foster D, Dhingra V, et al. Intensive versus conventional glucose control in critically ill patients. N Engl J Med. 2009;360:1283-97.

10. Chew ST, Mar WM, Ti LK. Association of ethnicity and acute kidney injury after cardiac surgery in a South East Asian population. Br J Anaesth. 2013;110: 397-401.

11. Ng RR, Chew ST, Liu W, Shen L, Ti LK. Identification of modifiable risk factors for acute kidney injury after coronary artery bypass graft surgery in an Asian population. J Thorac Cardiovasc Surg. 2014;147:1356-61.

12. Lazar HL. Glycemic control during coronary artery bypass graft surgery. ISRN Cardiol. 2012;2012:292490. 
13. Lazar HL, McDonnell M, Chipkin SR, Furnary AP, Engelman RM, Sadhu AR, et al. The Society of Thoracic Surgeons practice guideline series: blood glucose management during adult cardiac surgery. Ann Thorac Surg. 2009; 87:663-9.

14. Turina M, Fry DE, Polk HC Jr. Acute hyperglycemia and the innate immune system: Clinical, cellular and molecular aspects. Crit Care Med. 2005;33: 1624-33.

15. Yu WK, Li WQ, Li N, Li JS. Influence of acute hyperglycemia in human sepsis on inflammatory cytokine and counter-regulatory hormone concentrations. World $J$ Gastroenterol. 2003;9:1824-7.

16. Esposito K, Nappo F, Marfella R, Giugliano G, Giugliano F, Ciotola M, et al. Inflammatory cytokine concentrations are acutely increased by hyperglycemia in humans: role of oxidative stress. Circulation. 2002;106:2067-72.

17. Kaneshige H. Non-enzymatic glycosylation of serum $\operatorname{IgG}$ and its effect on antibody activity in patients with diabetes mellitus. Diabetes. 1987;36:822-8.
18. Delamaire M, Maugendre D, Moreno M, Le Goff MC, Allannic H, Genetet B Impaired leucocyte functions in diabetic patients. Diabet Med. 1997;14:29-34.

19. Latham R, Lancaster AD, Covington JF, Pirolo JS, Thomas CS Jr. The association of diabetes and glucose control with surgical site infection among cardiothoracic surgery patients. Infect Control Hosp Epidemiol. 2001;22:607-12.

20. Tan CE, Eammanuel SC, Tan BY, Jacob E. Prevalence of diabetes and ethnic difference in cardiovascular risk factors. The 1992 Singapore National Health Survey. Diabetes Care. 1999;22:241-7.

21. Tai ES, Eammanuel SC, Chew SK, Tan BY, Tan CE. Isolated low HDL cholesterol: an insulin-resistant state only in the presence of fasting hypertriglyceridemia. Diabetes. 1999;48:1088-92.

22. Finney SJ, Zekveld C, Elia A, Evans TW. Glucose control and mortality in critically ill patients. JAMA. 2003;290:2041-7.

23. Soo Hoo GW. Tight blood glucose control in the ICU: how best to measure glucose control? Chest. 2008;133:316-7.

\title{
EDITORIAL COMMENTARY
}

\section{The pros and cons of intensive insulin therapy}

\author{
Christoph Schimmer, MD
}

See related article on pages 323-8.

The pros and cons of intensive insulin therapy to prevent surgical site infections are still a matter of debate. Do the benefits of intensive insulin therapy outweigh the potential risk of increased occurrence of hypoglycemia?

The etiology of intraoperative and postoperative hyperglycemia, which is associated with increased morbidity and mortality, is the hormonal stress response to surgery, which induces insulin resistance in patients with and without diabetes. This leads to elevated levels of counterregulatory hormones, including cortisol, epinephrine, and growth hormone.

When talking about intensive versus conventional glucose control in critically ill patients, one has to point out the Normoglycaemia in Intensive Care Evaluation and Survival Using Glucose Algorithm Regulation (NICESUGAR) trial. This trial investigated 6104 patients who underwent random assignment (3054 were assigned to

From the Department of Cardiothoracic and Thoracic Vascular Surgery, University Hospital Würzburg, University of Würzburg, Würzburg, Germany.

Disclosures: Author has nothing to disclose with regard to commercial support.

Received for publication Sept 21, 2014; accepted for publication Sept 21, 2014; available ahead of print Oct 16, 2014.

Address for reprints: Christoph Schimmer, MD, Department of Cardiothoracic and Thoracic Vascular Surgery, University Hospital Würzburg, University of Würzburg, Oberdürrbacherstraße 6, 97080 Würzburg, Germany (E-mail: Schimmer_c@klinik.uni-wuerzburg.de).

J Thorac Cardiovasc Surg 2015;149:328-9

$0022-5223 / \$ 36.00$

Copyright (c) 2015 by The American Association for Thoracic Surgery

http://dx.doi.org/10.1016/j.jtcvs.2014.09.074 undergo intensive control with a target blood glucose range of $81-108 \mathrm{mg} / \mathrm{dL}$ and 3050 to undergo conventional control with a target of $\leq 180 \mathrm{mg} / \mathrm{dL}$ ). The study group concluded that intensive glucose control increased mortality among adults in the intensive care unit $(P=.02)$. Severe hypoglycemia $(\leq 40 \mathrm{mg} / \mathrm{dL})$ was reported to be present in $6.8 \%$ in the intensive control group versus $0.5 \%$ in the conventional control group $(P<.001){ }^{2}$

Trick and colleagues ${ }^{3}$ focused exclusively on cardiac surgical patients in terms of modifiable risk factors associated with deep sternal site infection after coronary artery bypass grafting. Trick and colleagues ${ }^{3}$ showed that appropriate timing of antimicrobial prophylaxis and control of preoperative blood glucose levels $(<200 \mathrm{mg} / \mathrm{dL})$ prevented deep sternal site infection after coronary artery bypass grafting operations.

To summarize the results of the existing international literature, Kao and associates ${ }^{4}$ performed a Cochrane review concerning the effect of intensive insulin therapy in the perioperative period on the incidence of surgical site infections, incidence of hypoglycemia, level of glycemic control, all-cause and infection-related mortalities, and hospital stay. Furthermore, Kao and associates ${ }^{4}$ investigated the effects of various levels of glycemic control. Only 1 trial (out of 5 randomized, controlled trials) demonstrated a significant reduction in surgical site infections with strict glycemic control, but the quality of this trial was difficult to assess as a result of poor reporting. Kao and associates ${ }^{4}$ concluded that there was insufficient evidence to support strict glycemic control versus conventional management (maintenance of glucose $<200 \mathrm{mg} / \mathrm{dL}$ ) for the prevention of surgical site infections. Further large randomized trials 